\title{
Hypoxia-Inducible Factor 1 Alpha Contributes to Cardiac Healing in Mesenchymal Stem Cells-Mediated Cardiac Repair
}

\author{
Inmaculada Cerrada, ${ }^{1,2}$ Amparo Ruiz-Saurí, ${ }^{3}$ Rubén Carrero, ${ }^{1}$ César Trigueros, ${ }^{4}$ Akaitz Dorronsoro, ${ }^{4}$ \\ Jose María Sanchez-Puelles, ${ }^{5}$ Antonio Diez-Juan, ${ }^{6}$ Jose Anastasio Montero, ${ }^{1}$ and Pilar Sepúlveda ${ }^{1}$
}

\begin{abstract}
Mesenchymal stem cells (MSC) are effective in treating myocardial infarction (MI) and previous reports demonstrated that hypoxia improves MSC self-renewal and therapeutics. Considering that hypoxia-inducible factor1 alpha (HIF-1 $\alpha$ ) is a master regulator of the adaptative response to hypoxia, we hypothesized that HIF- $1 \alpha$ overexpression in MSC could mimic some of the mechanisms triggered by hypoxia and increase their therapeutic potential without hypoxia stimulation. Transduction of MSC with HIF-1 $\alpha$ lentivirus vectors (MSC-HIF) resulted in increased cell adhesion and migration, and activation of target genes coding for paracrine factors. When MSC-HIF were intramyocardially injected in infarcted nude rats, significant improvement was found (after treatment of infarcted rats with MSC-HIF) in terms of cardiac function, angiogenesis, cardiomyocyte proliferation, and reduction of fibrotic tissue with no induction of cardiac hypertrophy. This finding provides evidences for a crucial role of HIF- $1 \alpha$ on MSC biology and suggests the stabilization of HIF- $1 \alpha$ as a novel strategy for cellular therapies.
\end{abstract}

\section{Introduction}

$\mathrm{M}$ YOCARDIAL INFARCTION (MI) is one of the main causes of mortality and morbidity in developed countries. Despite progress in primary angioplasty mortality remain high $[1,2]$.

Mesenchymal stem cells (MSC) have been used over the past years as a novel therapy to treat $\mathrm{MI}$ and clinical studies using MSC for cardiac tissue repair have been recently completed (Prometheus; http://clinicaltrials.gov).

To improve MSC therapeutics, many strategies have been conducted [3]. Preconditioning of MSC with hypoxia induced the pro-survival Akt pathway and increased their therapeutic potential in a model of hind limb ischemia [4]. Hypoxia-inducible transcription factors (HIFs) have been identified as pivot molecular mediators enabling cell adaptation to hypoxia [5-10] and these molecules have been correlated with cell survival [11-13]. Ischemic tissue elevates levels of HIF-1 $\alpha$, which in turn regulate the expression of nearly 200 genes affecting cellular responses to stress [13]. Genes regulated by HIF- $1 \alpha$ include vascular endothelial growth factor (VEGF), erythropoietin, angiopoietin, placental growth factor, and platelet-derived growth factor [14,15].
Culture of embryonic stem cells on fetal stromal cells overexpressing HIF- $1 \alpha$ improves their self-renewal and pluripotency in comparison with maintenance on fibroblast-based feeders [16]. The intracardiac injection of HIF-1 $\alpha$ naked DNA reduced the size of infarction and increased neovascularization in the ischemic heart [17].

HIF- $1 \alpha$ overexpression in MSC improved their survival and therapeutic properties [18-20]. Considering the impact of HIF$1 \alpha$ in the adaptative response to hypoxia we wanted to evaluate the impact of HIF activity on the therapeutic potential of MSC during the treatment of ischemic cardiac diseases.

\section{Materials and Methods}

All procedures were approved by the Instituto de Salud Carlos III and institutional ethical and animal care committees.

\section{Cells, culture conditions, and lentiviral labeling}

Human bone marrow MSC $(n=3$; Inbiobank San Sebastian) were cultured following manufacturer's instructions and lentivirally transduced with pWIPI-green fluorescent

\footnotetext{
${ }^{1}$ Regenerative Medicine and Heart Transplantation Unit, Fundación para la Investigación Hospital La Fe, Valencia, Spain.

${ }^{2}$ Universidad CEU-Cardenal Herrera, Valencia, Spain.

${ }^{3}$ Departamento de patología, Universidad de Valencia, Valencia, Spain.

${ }^{4}$ Fundación Inbiomed, San Sebastián, Spain.

${ }^{5}$ Centro de Investigaciones Biológicas, Consejo Superior de Investigaciones Científicas, Madrid, Spain.

${ }^{6}$ Centro de Investigación Príncipe Felipe, Valencia, Spain.
} 
protein (GFP) or pWIPI-HIF-GFP (http://addgene.org). To label the cells, supernatants containing retroviral particles obtained from the 293 packaging cell lines transduced with pWIPI-GFP or pWIPI-HIF-GFP were filtered through $0.45 \mu \mathrm{m}$ filter and added to MSC for $8 \mathrm{~h}$, and then replaced by fresh medium. Lentiviral transduction of MSC was performed by incubating cells for $8 \mathrm{~h}$ with lentiviral particles at a multiplicity of infection of 10 in MSC culture medium. Titration of lentiviral supernatants was performed in fresh HEK293T by our Viral Vector Unit (http://inbiomed.org). This procedure was repeated daily for 3 days. Transduction efficiency in MSC was evaluated by flow cytometry. Percentage of infection was routinely higher than $90 \%$.

\section{Flow cytometry}

Human MSC-GFP or MSC-HIF-GFP (passage 6-10) were analyzed by flow cytometry (Coulter EPICS XL flow cytometer; Beckman Coulter) to determine the percentage of GFP-positive cells after lentiviral transduction. Data acquisition and analyses were performed with Expo32 software (Beckman Coulter). The cells were processed according to standard protocols.

\section{Real-time polymerase chain reaction}

Total RNA was prepared as described above. cDNA was synthesized using M-MLV Reverse Trascriptase (Invitrogen; http://qiagen.com). Real-time polymerase chain reaction (qRT-PCR) was performed using LightCycler 480 SYBR Green I Master (Roche Molecular Biochemical; http://roche.com) with the LightCycler 480 (Roche) according to the manufacturer's instructions. Quantitative PCR employed the following conditions: $95^{\circ} \mathrm{C}$ at $10 \mathrm{~min}, 40$ cycles at $95^{\circ} \mathrm{C}, 15 \mathrm{~s}$; $58^{\circ} \mathrm{C}, 10 \mathrm{~s}$; and $72^{\circ} \mathrm{C}, 20 \mathrm{~s}$. The quality of the primers was tested by analysis of the melting curve using the following conditions: $95^{\circ} \mathrm{C}, 5 \mathrm{~s} ; 60^{\circ} \mathrm{C}, 15 \mathrm{~s}$; and $97^{\circ} \mathrm{C}$ continuous, 1 cycle. We analyzed the expression of genes that were already known gene targets or had been involved in hypoxia-related signaling. The primers were designed using the Primer-Blast online tool and oligonucleotide sequences are listed in Supplementary Table S1 (Supplementary Data are available online at www.liebertpub.com/scd).

\section{Western blot analysis}

Whole extracts from MSC or MSC-HIF were prepared in ice-cold lyses buffer using M-PER Mammalian Protein Extraction Reagent (Thermo Fisher Scientific; http://piercenet.com). Briefly, each sample was lysed in $150 \mu \mathrm{L}$ of lysis buffer, incubated on ice at $4^{\circ} \mathrm{C}$ for $30 \mathrm{~min}$, and centrifuged at $14,000 \mathrm{rpm}$ for $15 \mathrm{~min}\left(4^{\circ} \mathrm{C}\right)$. Protein concentration was determined using the BCA Protein Assay Kit (Thermo Fisher Scientific). Fifty micrograms of total protein were separated on $10 \%$ sodium dodecyl sulfate-polyacrylamide gels. Polyvinylidene fluoride membranes were incubated with anti-HIF-1 $\alpha$ (BD; http://bd.com), anti-Akt (Santa Cruz Biotechnology, Inc.; http://scbt.com), anti P-Akt Ser473 (Cell Signaling Technology, Inc.; http://cellsignaling.com), antiERK (Cell Signaling Technology, Inc.), anti P-ERK (Chemicon; http://chemicon.com), anti-p38MAPK (Cell Signaling Technology, Inc.), anti P-p38MAPK (Cell Signaling Technology, Inc.), anti-NFk $\beta$ (Santa Cruz Biotechnology, Inc.), anti P-NFк $\beta$ (Cell Signaling Technology, Inc.), anti-SAPK/
JNK (Cell Signaling Technology, Inc.) y anti P-SAPK/JNK (Cell Signaling Technology, Inc.), and anti-GAPDH (Chemicon) antibodies. Detection was carried out using ECL Plus ${ }^{\text {TM }}$ Western blotting detection reagents Amersham (GE healthcare; http://gehealthcare.com), according to the manufacturer's recommendations. Relative signal intensity was determined by densitometry using the software Image Quant TL (Amersham Biosciences).

\section{Wound healing assay}

Cells (MSC or MSC-HIF) were seeded in basal medium supplemented with $10 \%$ fetal bovine serum (FBS) and were grown to confluence onto gelatine-coated plates. The wound was made by scraping a plastic blue tip across the monolayer. Cells were allowed to migrate during $18 \mathrm{~h}$. After cell scratching, $18 \mathrm{~h}$ later, cultures were photographed with a camera coupled to a phase contrast microscope. Number of cells migrated through the scratched area were counted in MSC-HIF cultures and normalized versus MSC cultures. The assay was performed in duplicated wells and repeated 3 times.

\section{Adhesion assay}

Cells were seeded in basal medium onto cover slides previously treated with $10 \mu \mathrm{g} / \mathrm{cm}^{2}$ of fibronectin (SigmaAldrich), $2 \mu \mathrm{g} / \mathrm{cm}^{2}$ of laminin (Sigma-Aldrich) and $10 \mu \mathrm{g} /$ $\mathrm{cm}^{2}$ of collagen (Sigma-Aldrich). After $1 \mathrm{~h}$, adhered cells were fixed with $2 \%$ paraformaldehyde (PFA), washed with phosphate-buffered saline (PBS), labeled with 4',6-diamidino2-phenylindole (DAPI), and counted. The assay was performed in triplicated wells and repeated thrice with MSC from 2 different donors.

\section{MSC migration assay}

To study trophism induced in MSC or MSC-HIF by trophic factors, cells were seeded in basal medium (Dulbecco's modified Eagle's medium with $0.5 \%$ FBS) at 10,000 cells $/ \mathrm{cm}^{2}$ in the top chamber of an $8 \mu \mathrm{m}$-pore migration transwell (BD Falcon; http://bd.com). After overnight culture, interleukin (IL)-1 $\beta$ (25 ng/mL), IL-6 (25 ng/mL), IL-8 (25 ng/mL), tumor necrosis factor $(\mathrm{TNF}-\alpha)(20 \mathrm{ng} / \mathrm{mL})$, hepatocyte growth factor (HGF) (25 ng/mL), serum derived factor (SDF-1 $\alpha$ ) (20 ng/ $\mathrm{mL})$, or insulin growth factor (IGF) $(25 \mathrm{ng} / \mathrm{mL})$ was added to the bottom chamber filled with basal medium and migrating cells to the bottom side of the transwell membrane were quantified $4 \mathrm{~h}$ later. FBS (10\%) was used as positive controls. Briefly, cultures were fixed with 2\% PFA (Panreac Química), the inside of the transwells were wrapped with a cotton bud to remove nonmigrating cells, the membrane was cut and placed in a glass slide with the bottom side upward, and DAPI (Sigma-Aldrich) was added to stain the nuclei. The assay was performed in duplicated wells and repeated thrice with MSC from 3 different donors. Migrated cells were counted and values were represented as fold increase relative to MSC passive cell migration through membranes toward basal medium (untreated MSC).

\section{Animals}

Male nude rats weighing 200-250 g (HIH-Foxn1 rnu; Charles River Laboratories, Inc.) were used. Initial number of 
animals included in the study was 70 . Mortality in all groups due to surgical procedures was about $30 \%$.

\section{$\mathrm{MI}$ and cell transplantation}

Permanent ligation of the left coronary artery was performed as previously described [21]. Immediately after left descendent artery (LAD) ligation, rats were transplanted intramyocardically (saline, $2 \times 10^{5}$ MSC cells or $2 \times 10^{5}$ MSCHIF per animal in 3 injections of $5 \mu \mathrm{L}$ volume at 3 points of the infarct border zone with a Hamilton syringe).

\section{5-Ethynyl-2 -deoxyuridine treatment and analysis of proliferating cells}

After saline or cell transplantation, a group of animals was daily given $0.5 \mathrm{~mL}$ i.p. injection of 5-ethynyl-2'-deoxyuridine (EdU) $(50 \mathrm{mg} / \mathrm{kg}$ b.w., i.p.) for 2 weeks. EdU labeled cells in heart tissue were identified using an anti-EdU antibody (Abcam). Proliferation index was calculated as a percentage of EdU labeled nuclei per total of nuclei identified by DAPI staining. Identification of proliferating cardiomyocytes was performed by double staining with anti-EdU antibodies and anti-Troponin I, respectively (Chemicon International). About 10,000 cells were counted per animal.

\section{Functional assessment by echocardiography}

Transthoracic echocardiography was performed in rats under inhalatory anesthesia (Sevorane) using an echocardiographic system (General Electrics) equipped with a 10$\mathrm{MHz}$ linear-array transducer as previously reported [21]. Measurements were taken at baseline and post-transplantation (4 weeks). Left ventricular (LV) dimensions in end diastole (LVDd) and end systole (LVDs), anterior and posterior wall (AW and PW) thickness in diastole and systole, enddiastolic area (EDA), and end-systolic area (ESA) were measured. Fractional area change (FAC) was calculated as $[(E D A-E S A) / E D A] \times 100$. Fractional shortening $(F S)$ was calculated as $[(\mathrm{LVDd}-\mathrm{LVDs}) / \mathrm{LVDd}] \times 100$. Changes in $\mathrm{AW}$ were calculated as $(\mathrm{AWs}-\mathrm{AWd} / \mathrm{AWd}) \times 100$.

\section{Immunohistochemistry}

Four weeks post-implantation, animals were euthanized, the hearts removed, washed with PBS, and fixed in 2\% PFA. Heart tissue sections were prepared for immunohistochemistry as previously reported [22].

\section{Vascular density analysis}

Immunohistochemical detection of vessels was performed with anti-rat RECA (Chemicon International). Vessels were counted in 10 fields in the peri-infarct zone at $200 \times$ and referred as number of vessels per unit area $\left(\mathrm{mm}^{2}\right)$ using a light microscope and the Image Proplus 7.1 software.

\section{Morphometry}

The infarct zone in left ventricles was measured in 8-12 transverse sections of $7 \mu \mathrm{m}$ ( 1 slice each $200 \mu \mathrm{m}$ of tissue) from apex to base fixed with $2 \%$ PFA and stained with Masson's trichrome. The fibrotic zone was determined by computer planimetry (Image Proplus 7.1 software). Infarct size was expressed as percentage of total LV area and as a mean of all slices from each heart.

Cross-sectional cardiomyocyte area was measured in the border infarct zone of 3 heart sections from each animal stained with anti-laminin antibody (anti-laminin antibody; Abcam). Myocytes with defined sarcolemmal borders were selected for cross-sectional area measurements. Cardiomyocytes with different sizes $\left(0-1,100 \mu^{2}\right)$ were measured in 4 animals of each group (around 1,500 cells per animal in saline group and 3,000 cells in MSC or MSC-HIF group) as previously described [23]. Briefly, area of cardiomyocytes was measured by computer planimetry (Image Proplus 7.1 software) and the number of cardiomyocytes ranking from 0-100 $\mu \mathrm{m}, \quad 100-200 \mu \mathrm{m}, \quad 200-300 \mu \mathrm{m}, \quad 300-400 \mu \mathrm{m}, \quad 400$ $500 \mu \mathrm{m}, 500-600 \mu \mathrm{m}, 600-700 \mu \mathrm{m}, 700-800 \mu \mathrm{m}, 800-900 \mu \mathrm{m}$, $900-1,000 \mu \mathrm{m}$, and $1,000-1,100 \mu \mathrm{m}$ were calculated in each animal. Median and first and third quartile of small size cardiomyocytes $(0-200 \mu \mathrm{m})$ in each group were represented in box- and whisker plots using the Graphpad Prism 5 software.

Number of cardiomyocytes of a given size range were expressed as percentage of total cell count for each animal. Distribution frequency of cardiomyocyte cross-sectional areas in saline, MSC, and MSC-HIF groups, were represented in intervals of $100 \mu \mathrm{m}$ size with overlapping Gaussian curves using the Graphpad Prism 5 software.

\section{Statistical analysis}

Data are expressed as mean \pm standard error of the mean or median (interquartile range). Comparisons between control and experimental groups were done with the Wilcoxon W test or the Mann-Whitney U test, as appropriate. Analyses were conducted with SPSS and GraphPad Prism 5 software. Differences were considered statistically significant at $P<0.05$ with a $95 \%$ confidence interval.

\section{Results}

\section{HIF-1 $\alpha$ overexpression induces changes in MSC gene expression and cell signaling}

MSC were transduced with lentiviral vectors either pWIPIGFP (named as MSC) or pWIPI-HIF-GFP (named as MSCHIF). After infection, $90 \%-95 \%$ of cultured cells were GFP positive (Fig. 1B). HIF-1 $\alpha$ mRNA levels were elevated $4.88 \pm 0.57-$ fold (Fig. 1B) and MSC-HIF cultures expressed HIF$1 \alpha$ protein in normoxia (Fig. 1D).

Based on microarray analysis (article in preparation), we investigated the upregulation of different genes in MSC-HIF. Over 30 HIF target genes analyzed, we detected increased expression in 11 by RT-PCR (Figs. 2A and 3A; Table 1). These genes are implicated in angiogenesis (ANGPT1, APLN, CD3D, CTGF, and CYR61), cell survival (BNIP3, BNIP3L, and PIK3C3), extracellular matrix remodeling [fibroblast growth factor 2, transforming growth factor, beta 2 (TGF 32 )], and chemotaxis (c-MET). Notably, TGF $\beta 2$ was upregulated by $7.31 \pm 1.25$-fold, c-MET was upregulated by $3.88 \pm 0.22$ fold, and ANGPT1 was upregulated by $2.11 \pm 0.21$-fold. To investigate if non-hypoxic HIF stabilization had an impact in PI3K/Akt and MAPK pathways immunoblot analysis was carried out (Fig. 2B). Levels of phosphorylated Akt were 


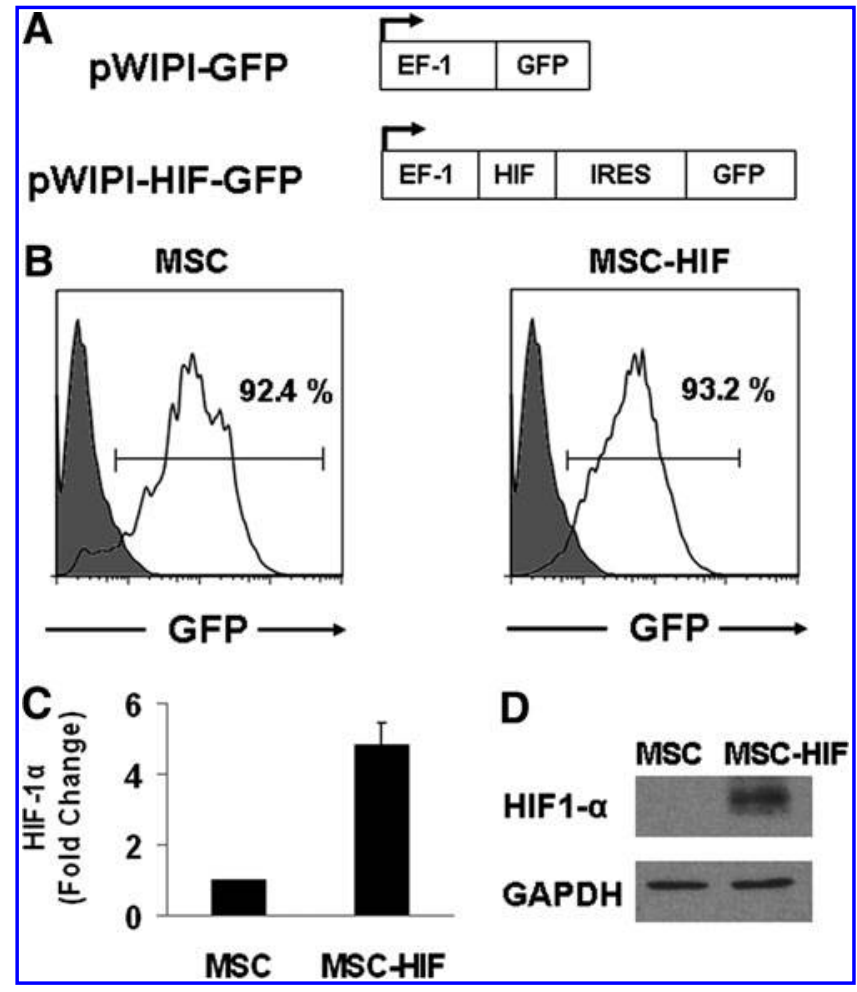

FIG. 1. Characterization of transduced MSC cultures. (A) pWIPI GFP and HIF-GFP lentiviral vectors. (B) Lentiviral labeling of human MSC with pWIPI-GFP or pWIPI-HIF-GFP yielded more than $90 \%$ of infection as detected by flow cytometric analysis of GFP. (C) mRNA levels of HIF-1 $\alpha$ in MSC and MSC-HIF populations as assessed by qRT-PCR fold change. (D) Expression of HIF-1 $\alpha$ protein in MSC and MSCHIF. GAPDH was used as protein loading control. Data represent the mean \pm SD of 3 independent experiments. MSC, mesenchymal stem cells; HIF, hypoxia-inducible factor 1 alpha; GFP, green fluorescent protein; qRT-PCR, quantitative real-time polymerase chain reaction; $\mathrm{SD}$, standard deviation.

increased (11.12 \pm 1.2 in MSC-HIF vs. 5.54 \pm 0.8 in MSC; $P<0.05)$. pMAPK $^{38}(0.87 \pm 0.15$ in MSC-HIF vs. $0.56 \pm 0.1$ in MSC; $P<0.5)$ and pMAPK $^{\mathrm{JNK}}(8.31 \pm 1.18$ in MSC-HIF vs. $2.07 \pm 0.41$ in MSC; $P<0.5)$ were also elevated indicating the positive effect of HIF stabilization in MSC proliferation and cell survival.

\section{HIF induces expression of adhesion molecules and promotes migration in response to trophic signals}

We next assayed the influence of HIF in MSC cell adhesion and migration (Fig. 3). Quantitative PCR showed increase in fold change expression of several genes implicated in cell adhesion (AMIGO 24.8 \pm 0.38 -fold, NCAM2 1.27 \pm 0.12 -fold, ITGA2 2.87 \pm 0.12 -fold, SDC1 $4.44 \pm 0.15$-fold, and SPARC $2.03 \pm 10$-fold) and extracellular matrix production (COLXII $3.59 \pm 0.69$-fold; Fig. 3A). In vitro experiments showed that HIF-1 $\alpha$ overexpression promoted cell spreading in a wound healing assay with $2.09 \pm 0.5$-fold increase at $18 \mathrm{~h}(P<0.01$; Fig. 3B). Cell adhesion to collagen $(1.31 \pm 0.02$-fold; $P<0.05)$ and laminin $(1.24 \pm 0.09$-fold; $P<0.05)$ was also increased in MSC-HIF versus MSC (Fig. 3C). To further investigate the role of HIF-1 $\alpha$ in MSC biology, cells were allowed to migrate



FIG. 2. Transduction of MSC with HIF- $1 \alpha$ vectors induce biological responses. (A) Quantification of gene transcription levels of several HIF target genes by qRT-PCR analysis in MSC-HIF cultures versus MSC cultures. Data are expressed as relative fold of control (normalized values) and represent the mean $\pm S D$ of 3 independent experiments. (B) Western blot analysis of kinase phosphorylation in MSC-HIF. Total cell lysates $(30 \mu \mathrm{g})$ were separated by sodium dodecyl sulfate-polyacrylamide gel electrophoresis and after blotting incubated with specific antibodies. Anti-GAPDH was used as loading control. Expression levels of phosphorylated proteins were quantified by densitometry of exposed films $\left({ }^{*} P<0.05\right)$.

toward trophic factors in a transwell culture system (Fig. 3D). Migration toward IL-6 (1.93 \pm 0.12 in MSC-HIF vs. $1.5 \pm 0.18$ in MSC; $P<0.05)$, HGF $(2 \pm 0.25$ in MSC-HIF vs. $1.12 \pm 0.12$ in MSC; $P<0.01)$, and SDF $(1.7 \pm 0.23$ in MSC-HIF vs. $1.17 \pm 0.02$ in MSC; $P<0.01)$ was significantly elevated. Consistent with results shown in Fig. 3A and B, we observed stronger changes in cytoskeletal architecture and actin reorganization detected by paxillin and phaloidin stainings in MSC-HIF versus MSC when cells were cultured under chemotactic stimulus of SDF (Fig. 3E). These results indicate that HIF-1 $\alpha$ induces morphologic/structural changes in MSC that in turn improve cell motility and response to trophism.

\section{MSC-HIF improve cardiac function in a rat model of $\mathrm{MI}$}

To test if HIF-1 $\alpha$ expression improved therapeutic properties of MSC during cardiac repair, MSC-HIF were transplanted in nude rats after induction of MI. Based on our 


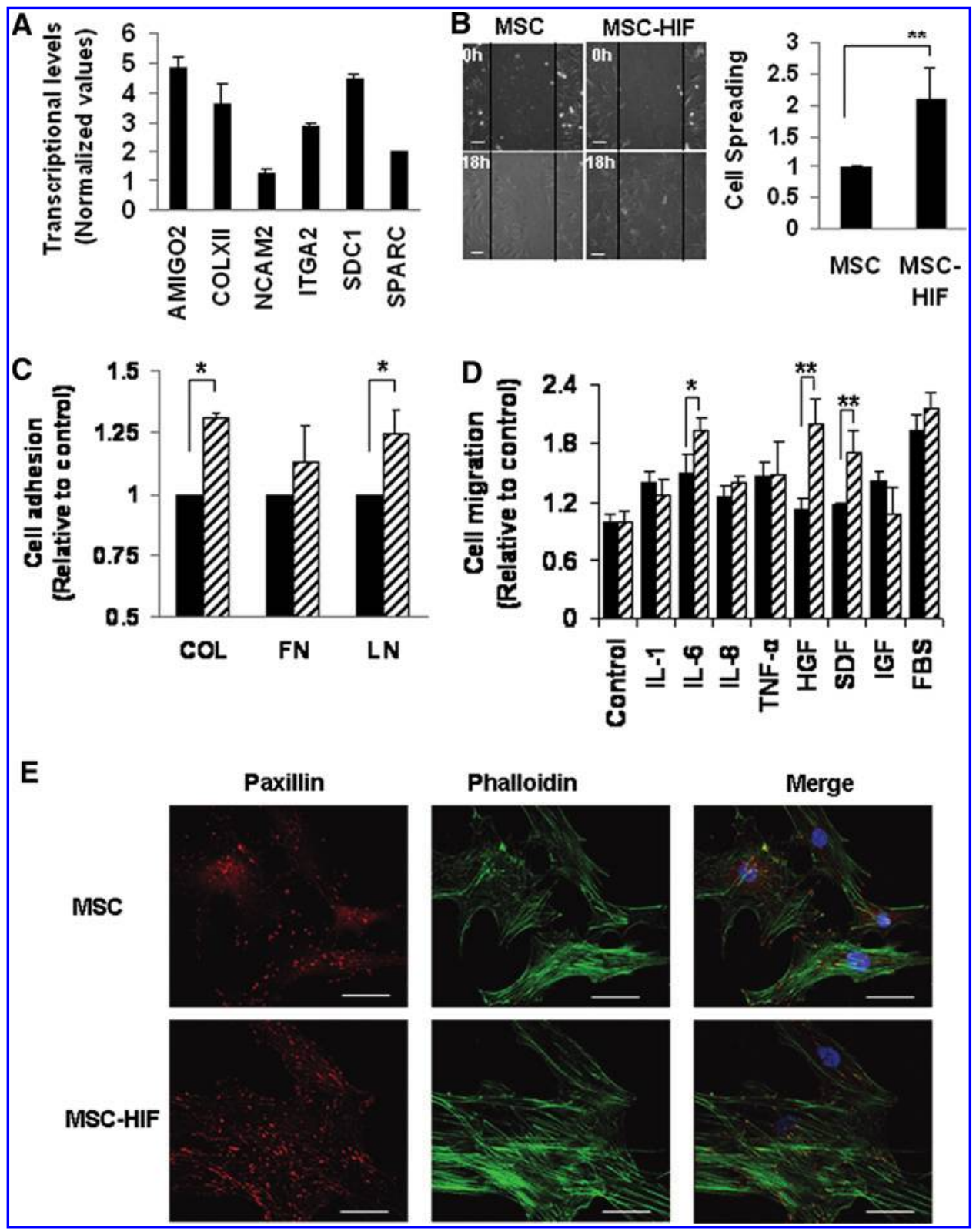

FIG. 3. HIF- $1 \alpha$ expression induces adhesion and migration of MSC. (A) Quantification of gene transcription levels of adhesion molecules and extracellular matrix proteins by qRT-PCR analysis in MSC-HIF cultures versus MSC cultures. Data are expressed as relative fold of control (normalized values) and represent the mean \pm SD of 3 independent experiments. (B) Photomicrograph images (200 $\times$ magnification) of cell spreading assay with MSC and MSC-HIF cultures (Scale bar $=100 \mu \mathrm{m})$. Number of cells migrated through the scratched region (delineated with black lines) were quantified. Differences were calculated after $18 \mathrm{~h}$ of initial cell scratching and values were normalized to MSC. (C) Adhesion of untreated MSC (black bars) and MSC-HIF (striped bars) to collagen, fibronectin, and laminin. Data are represented as fold increase relative to MSC control (mean \pm SD). (D) Migration of MSC or MSCHIF toward trophic factors IL-1 $\beta$ ( $25 \mathrm{ng} / \mathrm{mL}), \mathrm{IL}-6$ ( $25 \mathrm{ng} / \mathrm{mL}), \mathrm{IL}-8(25 \mathrm{ng} / \mathrm{mL}), \mathrm{TNF}-\alpha(20 \mathrm{ng} / \mathrm{mL}), \mathrm{HGF}(25 \mathrm{ng} / \mathrm{mL}), \mathrm{SDF}-1 \alpha$ $(20 \mathrm{ng} / \mathrm{mL}), \mathrm{IGF}-1(25 \mathrm{ng} / \mathrm{mL})$, and $10 \%$ FBS $\left({ }^{*} P<0.05,{ }^{* *} P<0.01\right.$, in different panels). (E) Double staining of MSC and MSC-HIF cultures with phalloidin (green label) and paxilin (red label) treated with SDF- $1 \alpha(25 \mathrm{ng} / \mathrm{mL})$. Nuclei were stained with DAPI (blue). Scale bar $=25 \mu \mathrm{m}$. DAPI, 4',6-diamidino-2-phenylindole; IL, interleukin; TNF- $\alpha$, tumor necrosis factor; HGF, hepatocyte growth factor; SDF, serum derived factor; IGF, insulin growth factor; FBS, fetal bovine serum.

previous observations [22] and to minimize inflammatory infiltrates due to stem cell transplantation, cell dose was adjusted to 200,000 cells/animal. Thus, saline solution, MSC or MSC-HIF were transplanted into the myocardium of rats shortly after induction of MI by LAD ligation. Four weeks after transplantation, cardiac function parameters were measured to assess the degree of functional recovery achieved by the presence of MSC or MSC-HIF in the infarct border zone. MSC-HIF group displayed a significant recovery of systolic function as calculated by percentage of FAC $(33.16 \% \pm 1.51 \%$ in saline group, $38.25 \% \pm 2.03 \%$ in MSC, and $44.01 \% \pm 1.14 \%$ in MSC-HIF; $P<0.0001$ in MSC-HIF vs. saline and $P<0.05$ in MSC-HIF vs. MSC in saline group) and FS $(23.23 \% \pm 0.79 \%$ in saline group, $24.96 \% \pm 1.48 \%$ in MSC and 
Table 1. Echocardiographic Values of Saline, Mesenchymal Stem Cells and Mesenchymal Stem Cells-Hypoxia-Inducible Factor Groups

\begin{tabular}{|c|c|c|c|c|c|c|c|c|c|c|}
\hline & \multirow{2}{*}{\multicolumn{2}{|c|}{$\begin{array}{l}\text { Saline } \\
(\mathrm{n}=13)\end{array}$}} & \multirow{2}{*}{\multicolumn{2}{|c|}{$\begin{array}{c}\text { MSC } \\
(\mathrm{n}=10)\end{array}$}} & \multirow{2}{*}{\multicolumn{2}{|c|}{$\frac{M S C-H I F}{(n=11)}$}} & \multirow{2}{*}{\multicolumn{4}{|c|}{$P$ values }} \\
\hline & & & & & & & & & & \\
\hline & Baseline & Final & Baseline & Final & Baseline & Final & ANOVA & $\begin{array}{l}\text { Saline } \\
\text { vs. MSC }\end{array}$ & $\begin{array}{l}\text { Saline } \\
\text { MSC-HIF }\end{array}$ & $\begin{array}{c}\text { MSC } \\
\text { vs. MSC-HIF }\end{array}$ \\
\hline AWd & $1.60 \pm 0.03$ & $1.04 \pm 0.03$ & $1.40 \pm 0.03$ & $1.03 \pm 0.03$ & $1.47 \pm 0.03$ & $1.27 \pm 0.11$ & & & & \\
\hline $\mathrm{LVd}$ & $5.84 \pm 0.08$ & $7.44 \pm 0.16$ & $5.14 \pm 0.20$ & $6.95 \pm 0.27$ & $5.39 \pm 0.19$ & $7.03 \pm 0.17$ & & & & \\
\hline PWd & $1.46 \pm 0.05$ & $1.58 \pm 0.08$ & $1.44 \pm 0.04$ & $1.38 \pm 0.11$ & $1.44 \pm 0.09$ & $1.58 \pm 0.08$ & & & & \\
\hline AWs & $2.44 \pm 0.05$ & $1.35 \pm 0.04$ & $2.31 \pm 0.12$ & $1.37 \pm 0.05$ & $2.37 \pm 0.07$ & $1.77 \pm 0.16$ & & & & \\
\hline LVs & $3.43 \pm 0.05$ & $5.68 \pm 0.16$ & $2.92 \pm 0.11$ & $5.21 \pm 0.20$ & $3.15 \pm 0.14$ & $4.91 \pm 0.14$ & & & 0.003 & \\
\hline PWs & $2.13 \pm 0.09$ & $2.08 \pm 0.12$ & $2.04 \pm 0.08$ & $1.97 \pm 0.09$ & $2.09 \pm 0.07$ & $2.14 \pm 0.07$ & & & & \\
\hline EDA & $31.41 \pm 0.64$ & $44.38 \pm 1.55$ & $27.29 \pm 1.39$ & $44.12 \pm 2.10$ & $25.91 \pm 1.23$ & $41.73 \pm 1.69$ & & & & \\
\hline ESA & $8.66 \pm 0.40$ & $29.67 \pm 1.36$ & $7.64 \pm 0.47$ & $27.36 \pm 1.85$ & $7.61 \pm 0.49$ & $22.93 \pm 1.41$ & & & 0.002 & \\
\hline FS & $41.23 \pm 0.70$ & $23.23 \pm 0.79$ & $43.23 \pm 1.00$ & $24.96 \pm 1.48$ & $41.72 \pm 0.96$ & $30.15 \pm 0.90$ & & & 0.0007 & 0.03 \\
\hline FAC & $72.42 \pm 1.11$ & $33.16 \pm 1.51$ & $71.86 \pm 1.57$ & $38.25 \pm 2.03$ & $70.53 \pm 1.02$ & $44.01 \pm 1.14$ & & 0.02 & 0.0001 & 0.01 \\
\hline AWT & $34.49 \pm 0.85$ & $22.64 \pm 0.76$ & $38.95 \pm 1.75$ & $24.73 \pm 1.59$ & $37.75 \pm 0.70$ & $26.74 \pm 0.92$ & & & 0.008 & \\
\hline
\end{tabular}

All values are mean \pm SEM. AWd, LVd, PWd, AWs, LVs, and PWs are expressed in mm, whereas EDA and ESA are expressed in mm². FS, FAC, and AWT are expressed as percentage.

MSC, mesenchymal stem cells; HIF, hypoxia-inducible factor; ANOVA, analysis of variance; AWd, anterior wall diastole thickness; AWs, anterior wall systole thickness; AWT, anterior wall thickening; EDA, end-diastolic area; ESA, end-systolic area; FAC, fractional area change; FS, fractional shortening; LVd, left ventricular diastole internal dimension; LVs, left ventricular systole internal dimension; MI, myocardial infarction; PWd, posterior wall diastole thickness; PWs, posterior wall systole thickness; SEM, standard error of the mean.

$30.15 \% \pm 0.90 \%$, in MSC-HIF; $P<0.0001$ in MSC-HIF vs. MSC). Beneficial effects were also observed on anterior wall thickening (AWT) at this time point (AWT: $22.64 \% \pm 0.76 \%$ in saline group, $24.73 \% \pm 1.59 \%$ in MSC, and $26.74 \% \pm 0.92 \%$ in MSC-HIF; $P<0.01$ in MSC-HIF vs. saline; Fig. 4; Table 1).

\section{MSC-HIF reduce fibrotic scar tissue and induce angiogenesis}

Treatment with MSC-HIF significantly reduced the area of fibrous scar tissue (Fig. 5A); percentage of scar tissue was
$29.91 \% \pm 1.72 \%$ in saline group $(n=8), 18.12 \% \pm 0.93$ in MSC group $(n=6)$, and $12.73 \% \pm 1.04 \%$ in MSC-HIF group $(n=11)$ $(P<0.00001$ in MSC-HIF vs. saline, $P<0.0001$ in MSC vs. saline, and $P<0.01$ in MSC-HIF vs. MSC). Measurement of angiogenesis at the same time point showed that both MSC and MSC-HIF transplantation increased the number of vessels at the peri-infarct (Fig. 5B). Number of capillaries per $\mathrm{mm}^{2}$ was $518 \pm 81$ in saline, $810 \pm 53$ in MSC, and $1,252 \pm 80$ in MSC-HIF $(P<0.0001$ in MSC-HIF vs. saline, $P<0.01$ in MSC-HIF vs. MSC and in MSC vs. saline).
FIG. 4. Improvement of LV function in MSC-HIF-treated animals. (A) Representative echocardiographic images of 1 animal from saline $(n=13)$, MSC $(n=10)$ and MSC-HIF $(n=11)$ groups. Quantified values of area fractional change (FAC). (B) Representative 2dimensional systolic frame showing differences in wall motion. Quantified values of fractional shortening (FS) and anterior wall thickness (AWT) are given. Data are expressed as mean \pm SEM. $\quad\left({ }^{*} P<0.05\right.$, ${ }^{* *} P<0.01,{ }^{* * *} P<0.001$ in both panels). LV, left ventricular; SEM, standard error of the mean.

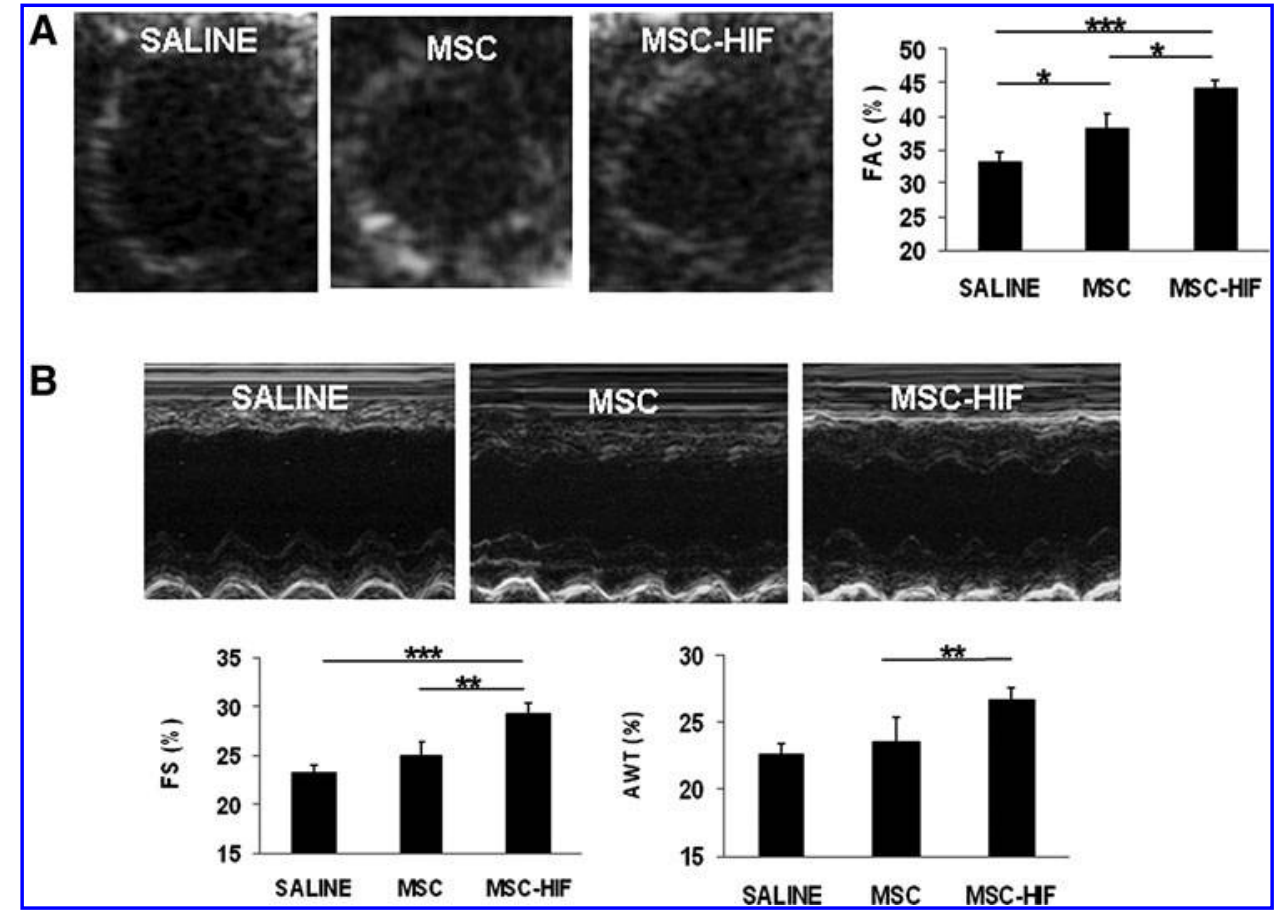




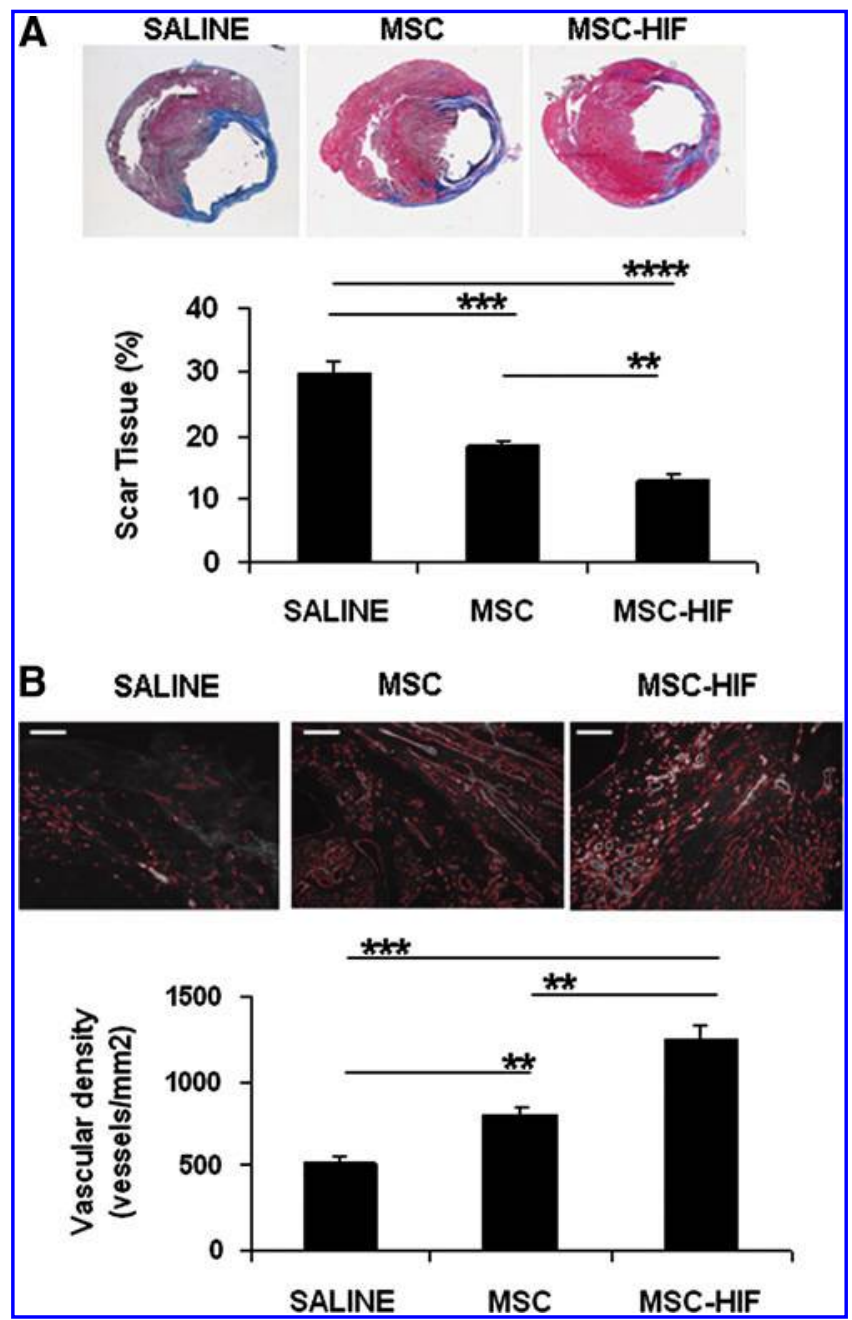

FIG. 5. Effect of MSC-HIF transplantation on infarct size and angiogenesis. (A) Representative heart sections from infarcted nude rats receiving saline $(n=8)$, MSC $(n=6)$, or MSC-HIF $(n=11)$. Fibrotic area (blue color) in the LV was calculated in Masson's Trichrome-stained sections. Animals were euthanized 4 weeks post-transplantation. Values are the mean \pm SEM. (B) Representative sections of saline, MSC, and MSC-HIF-treated animals ( $n=9$ in each group) stained with anti-RECA (red), and quantification of the total number of vessels in different groups (lined in white) using an image analyzer software. Scale bar $=200 \mu \mathrm{m} .{ }^{* *} P<0.01,{ }^{* * *} P<0.001$, $* * * * P<0.0001$ in both panels).

\section{MSC-HIF treatment promotes myocardial tissue regeneration}

Next, we analyzed the number of proliferating cells in the border zone of EdU-treated animals ( $n=6$ in each group). After 2 weeks, animals treated daily with EdU were sacrificed and the infarcted area was subjected to histological studies. At the doses analyzed, we did not detect engrafted cells in cell-treated animals. However, cell transplantation increased proliferation in heart tissue (Fig. 6A). Proliferation Index was $17.81 \% \pm 2.86 \%$ in saline, $26.82 \% \pm 3.05 \%$ in MSC, and $22.44 \% \pm 1.22 \%$ in MSC-HIF; $P<0.05$ in MSC and MSC-HIF vs. saline). Double staining Edu/Troponin I revealed the presence of proliferating cardiomyocytes. Cardiomyocyte proliferation index was $2.32 \% \pm 0.34 \%$ in saline group ( $n=5), 2.86 \% \pm 0.18 \%$ in MSC group $(n=6)$, and $4.39 \% \pm 0.61 \%$ in MSC-HIF group $(n=5) ;(P<0.05$ in MSC vs. saline and $P<0.01$ in MSC-HIF vs. saline). These results point to a paracrine effect as a mechanism induced by cell transplantation.

Finally, we wanted to evaluate if cardiac hypertrophy contributed to the increase in myocardial tissue in animals transplanted with MSC or MSC-HIF. For this purpose, cardiomyocyte area in the border zone of the infarct was calculated from heart sections stained with anti-laminin and anti-troponin I antibodies (Fig. 6B). Small size cardiomyocytes (less than $200 \mu \mathrm{m}^{2}$ ) were more abundant in cell-treated animals $(16.21 \pm 2.47$ in saline, $24.34 \pm 7.28$ in MSC, and $27.13 \pm 4.45$ in MSC-HIF; $P<0.05$ in MSC-HIF vs. saline) (Fig. 6C). However, when analyzing cardiomyocyte global sizes, we observed that relative to saline-treated animals, in both MSC and MSC-HIF groups the distribution of myocyte crosssectional area was shifted to the left with no significant differences in cardiomyocyte area, indicating the absence of cardiac hyperthrophy.

\section{Discussion}

HIF- $1 \alpha$ plays different roles in cardiac tissue that have been extensively studied [7]. While accumulation of HIF- $1 \alpha$ in cardiomyocytes lead to reduced contractility in the adult and deterioration of ventricular function [24,25], overexpression of these transcription factor attenuated cardiac dysfunction following MI probably due to an increase in blood perfusion and glycolysis and reduction of apoptosis $[12,13,26]$. In this context, stabilization of HIF- $1 \alpha$ in inducible polylhydroxylases (PHD) knockout mice (Phd $2^{\text {flox/flox }}$ mice) lead to an HIF-dependent tissue protection in case of MI, with increased capillary density and preserved cardiac structure and function [27]. The authors reported that the success of the approach was to avoid HIF stabilization during heart development, preventing the activation of detrimental pathways, while modulating the expression of PHD2 in the adult. Considering the dangerous potential of HIF- $1 \alpha$ stabilization in cardiac tissue, we wanted to potentiate HIFinduced therapeutic mechanisms, without modulation of HIF levels within the heart, using cell therapy.

MSC are an attractive approach to repair ischemic tissues and hypoxia is considered an important stimulus to potentiate their therapeutic mechanisms [28]. In a previous study, we reported that MSC reduced scar tissue formation and increased neovascularization more efficiently than other adult stem cell types [22]. The MSC-dependent paracrine mechanisms observed in vivo seemed to be triggered by hypoxia, since cells injected in the viable myocardium at the border zone often migrated to the ischemic fibrotic tissue, indicating not only a homing to the site of injury but also the ability of these cells to survive in hypoxic environments. Indeed, physiological niches of bone marrow stem cells display reduced oxygen levels and this condition is essential to maintain their self-renewal capacity and pluripotency [29].

Following this rationale, we wanted to investigate the effect of a constitutive form of HIF- $1 \alpha$ in MSC biology and therapeutics. This new strategy could be important to: (1) manipulate MSC in normoxia to mimic some of the effects induced by hypoxia, (2) identify the mechanisms by which MSC increase their survival and paracrine effects, and (3) 


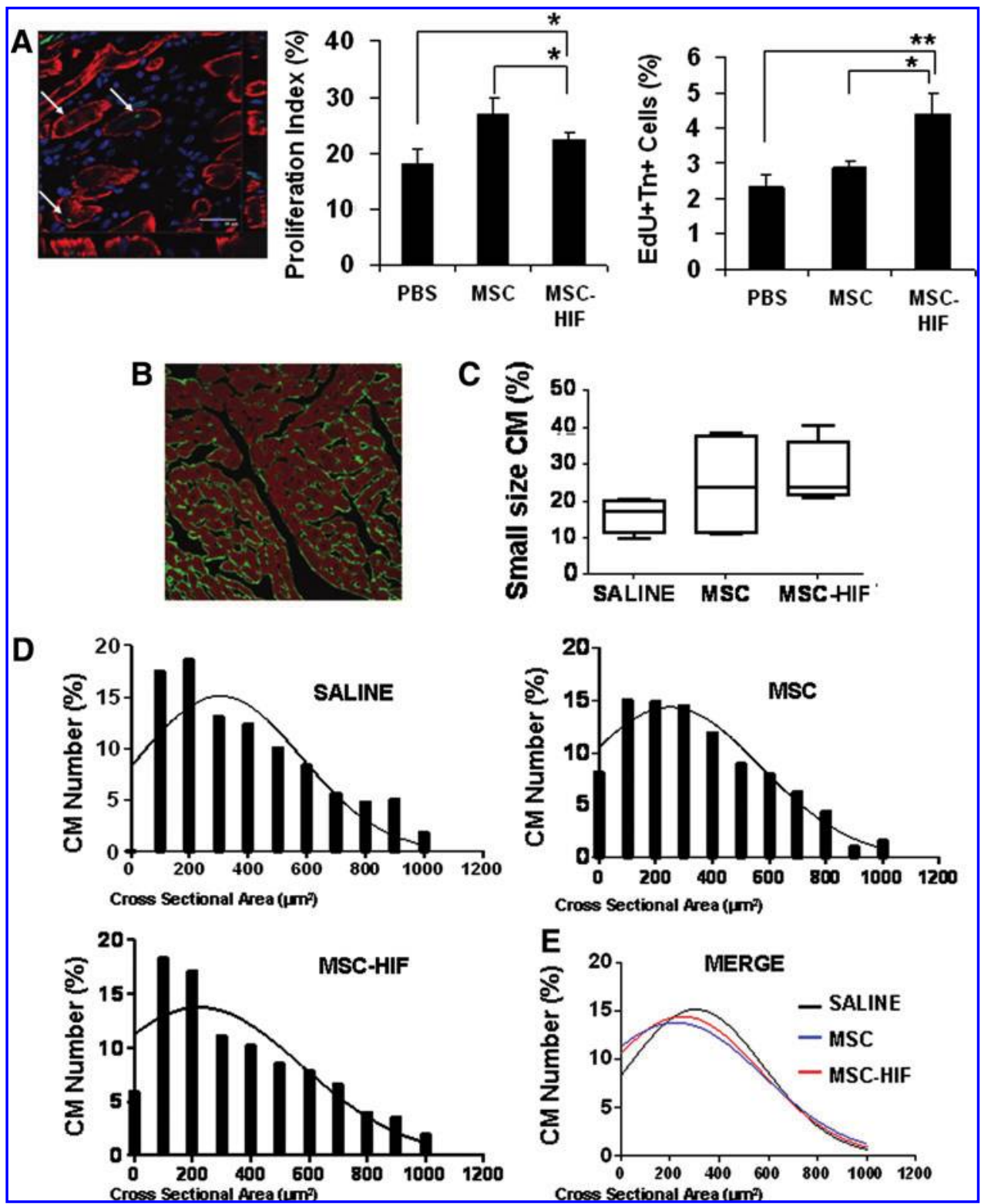

FIG. 6. MSC-HIF-treated animal showed increase in cardiomyocyte proliferation with no hypertrophy of heart tissue. (A) Confocal image of double staining with anti-Tn I (red) and anti-EdU (green) antibodies of a heart section from an MSC-HIFtreated animal (arrow points show double labeled proliferating cardiomyocytes). Nuclei are labeled with DAPI (blue). Scale bar $=30 \mu \mathrm{m}$ (image at $400 \times$ magnification). Proliferation index (number of EdU ${ }^{+}$cells/total nuclei) $\times 100$ and cardiomyocyte proliferation index $\left(\mathrm{EdU}^{+} \mathrm{TnI}^{+}\right.$cells/total TnI + DAPI +$) \times 100$ are indicated as a percentage. $\left({ }^{*} P<0.05,{ }^{* *} P<0.01\right)$. (B) Representative fluorescent image of a heart section double stained with anti-laminin (green) and anti-troponin I (red) antibodies (200× magnification). Myocyte regions at the border zone were selected for analysis of cross-sectional area. (C) Box plots showing cross-sectional area of small cardiomyocytes $(0-200 \mu \mathrm{m})$ detected in saline, MSC, and MSC-HIF groups. Boxes show the median and the 25th and 75th percentile. $P<0.05$ in MSC-HIF versus saline. (D) Distribution frequency of myocyte crosssectional areas at the border zone in saline $(n=4)$, MSC $(n=4)$, and MSC-HIF $(n=5)$ groups. Around 3,000 cardiomyocytes were analyzed per animal. Mean of cardiomyocytes ranking from 0 to 1,200 $\mu \mathrm{m}^{2}$ with intervals of $100 \mu \mathrm{m}$ are indicated and represented with Gaussian curves. (E) Merge of Gaussian curves representing cardimyocyte distribution size corresponding to saline (black line), MSC (blue line), and MSC-HIF (red line) groups. No significant differences were observed among groups indicating the absence of cardiac hypertrophy in cell-treated groups. EdU, 5-ethynyl-2'-deoxyuridine

determine HIF target molecules in MSC that could contribute to hypoxia-induced MSC phenotype.

MSC-HIF were analyzed by western blot and RT-PCR to determine HIF-1 $\alpha$ expression levels at mRNA and protein level. Analysis of the main signaling pathways activated in MSC-HIF revealed that HIF- $1 \alpha$ accumulation activated
PI3K/Akt. These results are consistent with previous reports showing that HIF stabilization promotes AKT phosphorylation in MSC [18]. Moreover, it has been suggested that PI3K/ Akt are linked to the phosphorylation of the MAPK and SAPK/JNK pathways in MSC and other cell types, which could explain the increase in phosphorylation of p38MAPK 
and SAPK/JNK kinases in MSC-HIF. Since constitutive expression of HIF- $1 \alpha$ induced Akt and SAP/JNK phosphorylation in MSC-HIF (Fig. 2) we hypothesize a possible autocrine loop among these molecules in MSC. Other mechanisms like downregulation of E2A-p21 by HIF-TWIST axes has also been reported to preserve MSC self-renewal capacity and to reduce senescence [28].

We next investigated the impact of HIF- $1 \alpha$ on MSC gene expression. Gain-of-function studies in MSC showed that HIF- $1 \alpha$ coordinately regulated the expression of genes encoding proteins and growth factors implicated in wound repair, angiogenesis, and extracellular matrix production, most of them previously described as HIF targets [30-35]. Proangiogenic factors including angiopoietin (ANGPT1), apelin (APLN), and the matricellular protein CYR61 (CNN1) were upregulated in MSC-HIF. Expression of ANGPT1 and APLN1 is modulated by hypoxia and HIF- $1 \alpha$ in cardiac myocytes and both promote beneficial effects on cardiac function and blood pressure [32,34]. Similarly, the proangiogenic factor CYR61 (CNN1) has been implicated in fibroblast senescence as a mechanism for controlling fibrogenesis in wound healing [36]. Strikingly, we do not observe upregulation of VEGF mRNA levels in MSC-HIF. Similar results were observed at the protein level in a cytokine assay of MSC-HIF/MSC culture supernatants (not shown). A possible explanation is that MSC express high levels of VEGF in normoxia that make difficult the detection of changes in VEGF levels between MSC-HIF and MSC.

TGF $\beta$ and connective tissue factor (CTGF) are also HIF target genes. Several studies suggested that TGF $\beta$ may be crucial for stem cell-based myocardial repair by repression of inflammatory gene synthesis mediating resolution of the inflammatory infiltrate $[37,38]$. In addition, TGF $\beta$ increases cell adhesion and regulates matrix metalloproteinases required for MSC migration through extracellular matrix barriers [39]. In this context, CTGF is a downstream mediator of both TGF $\beta$ signaling [40] and G-coupled protein receptor 30 (GPER), and recently its activation in HL-1 cardiomyocytes have been linked to stabilization of HIF- $1 \alpha$ and associated to anti-apoptotic mechanisms [41,42].

In addition, expression of integrins and genes related to connective tissue synthesis, and cytosqueleton reorganization were upregulated in MSC-HIF, that in turn improved wound healing and MSC locomotory behavior in functional studies of chemotaxis (Fig. 3).

BNIP3/BNIP3L are 2 HIF targets genes that also were upregulated in MSC-HIF. The activation of these molecules may seem contradictory with the rest of survival signals triggered by HIF- $1 \alpha$ overexpression, since they belong to the intrinsic mitochondria-linked death pathway. However, the alternative splicing of BNIP3 in ventricular myocytes during hypoxia has been recently described as a novel defense mechanism [43]. Thus, a similar mechanism cannot be discarded in MSC-HIF.

Of particular relevance was the increased migration toward SFD and HGF. These 2 molecules are implicated in the CXCR4 and c-Met axis respectively, that not only are activated in response to hypoxia, but also mediate the migration and homing of bone marrow-derived cells in vivo $[29,44-46]$. All these biological processes could be responsible for an improved MSC-mediated cardiac healing.
Thus, the major findings of this study are: (1) HIF-1 $\alpha$ triggers activation of PI3K/Akt, p38MAPK, and MAPK/JNK signaling pathways, (2) HIF- $1 \alpha$ overexpression increases cell adhesion and induces structural changes and cytoskeleton reorganization, (3) HIF- $1 \alpha$ increases cellular responses to trophics factors in vivo and in vitro, (4) MSC-HIF showed increased ability to repair cardiac function in an experimental model of MI, in correlation with increased ability to induce angiogenesis and decrease tissue fibrosis, and (5) Intracardiac injection of MSC-HIF induced cardiomyocyte proliferation in the absence of cardiac hyperthrophy.

These results are in accordance with previous studies in models of calvarial defects showing that treatment with MSC overexpressing HIF- $1 \alpha$ promote angiogenesis and osteogenesis [20]. These kinds of approaches, together with others based on direct stabilization of HIF- $1 \alpha$ in ischemic tissues, has led to phase I and II clinical studies in patients with severe pheripheral arterial disease [47].

Only 2 PHD inhibitors, FG-2216 and FG-4592, have progressed to clinical setting (http://clinicaltrials.gov/identifiers NCT00456053, NCT00761657), but it is conceivable that other drugs will be discovered and approved soon. In this context, the stabilization of HIF- $1 \alpha$ in MSC-HIF cultures could be useful for the screening of new drugs aiming to modulate HIF activity.

A limitation of our approach is that we have examined the action of HIF- $1 \alpha$ in normoxia in vitro, so we cannot discard additional mechanisms in hypoxic culture. However, the observed in vivo effects are likely to be more accurate and to recapitulate the effects of HIF- $1 \alpha$ in hypoxic environments resulting from cardiac ischemia.

Overall, this study demonstrates that HIF-1 $\alpha$ expression in MSC potentiates therapeutic mechanisms and adds new information about the repair processes induced by MSC.

\section{Acknowledgments}

This work was supported in part by grants from the Instituto de Salud Carlos III for the Regenerative Medicine Program of Valencian Community to Centro de Investigación Principe Felipe, KUTXA founding and from the FIS (PI07/784, CP08/80 and PI10/00743). P.S. acknowledges support from Miguel Servet and RETICS programs (Instituto de Salud Carlos III). We thank Dr. R. Muñoz-Chapuli for critical discussion. We also thank Dr. Ortiz de Landazuri for the gift of HIF- $1 \alpha$ plasmid, M. Sirerol for cloning assays, E. Nuñez and L. Pardo for immunological studies, M.P. Rubio for western blot analysis, and the service of confocal microscopy at CIPF for technical assistance.

\section{Author Disclosure Statement}

All authors have reported that they have no relationships relevant to disclose.

\section{References}

1. Anderson JL, CD Adams, EM Antman, CR Bridges, RM Califf, DE Casey, Jr., WE Chavey, 2nd, FM Fesmire, JS Hochman, et al. (2011). 2011 ACCF/AHA focused update incorporated into the ACC/AHA 2007 guidelines for the management of patients with unstable angina/non-ST-elevation myocardial infarction: a report of the American College of Cardiology 
Foundation/American Heart Association Task Force on Practice Guidelines. Circulation 123:e426-e579.

2. Patel MR, GJ Dehmer, JW Hirshfeld, PK Smith, JA Spertus, FA Masoudi, GJ Dehmer, MR Patel, PK Smith, et al. (2012). ACCF/SCAI/STS/AATS/AHA/ASNC/HFSA/SCCT 2012 appropriate use criteria for coronary revascularization focused update: a report of the American College of Cardiology Foundation Appropriate Use Criteria Task Force, Society for Cardiovascular Angiography and Interventions, Society of Thoracic Surgeons, American Association for Thoracic Surgery, American Heart Association, American Society of Nuclear Cardiology, and the Society of Cardiovascular Computed Tomography. J Thorac Cardiovasc Surg 143:780-803.

3. Samper E, A Diez, JA Montero and P Sepúlveda. (2012). Cardiac cell therapy: boosting mesenchymal stem cells effects. Stem Cell Rev. [Epub ahead of print]; DOI:10.1007/ s12015-012-9353-Z.

4. Rosova I, M Dao, B Capoccia, D Link and JA Nolta. (2008). Hypoxic preconditioning results in increased motility and improved therapeutic potential of human mesenchymal stem cells. Stem Cells 26:2173-2182.

5. Semenza GL. (2003). Targeting HIF-1 for cancer therapy. Nat Rev Cancer 3:721-732.

6. Lisy K and DJ Peet. (2008). Turn me on: regulating HIF transcriptional activity. Cell Death Differ 15:642-649.

7. Majmundar AJ, WJ Wong and MC Simon. (2010). Hypoxiainducible factors and the response to hypoxic stress. $\underline{\mathrm{Mol}}$ Cell 40:294-309.

8. Wang GL, BH Jiang, EA Rue and GL Semenza. (1995). Hypoxia-inducible factor 1 is a basic-helix-loop-helix-PAS heterodimer regulated by cellular $\mathrm{O} 2$ tension. Proc Natl Acad Sci U S A 92:5510-5514.

9. Wenger RH. (2002). Cellular adaptation to hypoxia: $\mathrm{O}_{2-}$ sensing protein hydroxylases, hypoxia-inducible transcription factors, and $\mathrm{O}_{2}$-regulated gene expression. FASEB J 16:1151-1162.

10. González IR, V Moreno-Manzano, FJ Rodriguez-Jimenez, P Sepúlveda and JM Sánchez-Puelles. (2011). The biology of HIF proteins in cell differentiation and disease. Vitam Horm 87:367-379.

11. Jiang C, H Lu, KA Vincent, S Shankara, AJ Belanger, SH Cheng, GY Akita, RA Kelly, MA Goldberg and RJ Gregory. (2002). Gene expression profiles in human cardiac cells subjected to hypoxia or expressing a hybrid form of HIF-1 alpha. Physiol Genomics 8:23-32.

12. Kido M, L Du, CC Sullivan, X Li, R Deutsch, SW Jamieson and PA Thistlethwaite. (2005). Hypoxia-inducible factor 1alpha reduces infarction and attenuates progression of cardiac dysfunction after myocardial infarction in the mouse. I Am Coll Cardiol 46:2116-2124.

13. Loor G and PT Schumacker. (2008). Role of hypoxia-inducible factor in cell survival during myocardial ischemiareperfusion. Cell Death Differ 15:686-690.

14. Pichiule P, JC Chavez and JC LaManna. (2004). Hypoxic regulation of angiopoietin-2 expression in endothelial cells. I Biol Chem 279:12171-12180.

15. Wang GL and GL Semenza. (1993). Desferrioxamine induces erythropoietin gene expression and hypoxia-inducible factor 1 DNA-binding activity: implications for models of hypoxia signal transduction. Blood 82:3610-3615.

16. Ji L, YX Liu, C Yang, W Yue, SS Shi, CX Bai, JF Xi, X Nan and XT Pei. (2009). Self-renewal and pluripotency is maintained in human embryonic stem cells by co-culture with human fetal liver stromal cells expressing hypoxia inducible factor 1alpha. I Cell Physiol 221:54-66.

17. Shyu KG, MT Wang, BW Wang, CC Chang, JG Leu, P Kuan and H Chang. (2002). Intramyocardial injection of naked DNA encoding HIF-1alpha/VP16 hybrid to enhance angiogenesis in an acute myocardial infarction model in the rat. Cardiovasc Res 54:576-583.

18. Liu XB, JA Wang, ME Ogle and L Wei. (2009). Prolyl hydroxylase inhibitor dimethyloxalylglycine enhances mesenchymal stem cell survival. J Cell Biochem 106:903-911.

19. Stubbs SL, ST Hsiao, HM Peshavariya, SY Lim, GJ Dusting and RJ Dilley. (2012). Hypoxic preconditioning enhances survival of human adipose-derived stem cells and conditions endothelial cells in vitro. Stem Cells Dev 21:1887-1896.

20. Zou D, Z Zhang, D Ye, A Tang, L Deng, W Han, J Zhao, S Wang, W Zhang, et al. (2011). Repair of critical-sized rat calvarial defects using genetically engineered bone marrowderived mesenchymal stem cells overexpressing hypoxiainducible factor-1alpha. Stem Cells 29:1380-1390.

21. Gandia C, A Arminan, JM Garcia-Verdugo, E Lledo, A Ruiz, MD Minana, J Sanchez-Torrijos, R Paya, V Mirabet, et al. (2008). Human dental pulp stem cells improve left ventricular function, induce angiogenesis and reduce infarct size in rats with acute myocardial infarction. Stem Cells 26:638-645.

22. Arminan A, C Gandia, JM Garcia-Verdugo, E Lledo, C Trigueros, A Ruiz-Sauri, MD Minana, P Solves, R Paya, JA Montero and P Sepulveda. (2010). Mesenchymal stem cells provide better results than hematopoietic precursors for the treatment of myocardial infarction. J Am Coll Cardiol 55:2244-2253.

23. Tang XL, G Rokosh, SK Sanganalmath, F Yuan, H Sato, J Mu, S Dai, C Li, N Chen, et al. (2010). Intracoronary administration of cardiac progenitor cells alleviates left ventricular dysfunction in rats with a 30-day-old infarction. Circulation 121:293-305.

24. Bekeredjian R, CB Walton, KA MacCannell, J Ecker, F Kruse, JT Outten, D Sutcliffe, RD Gerard, RK Bruick and RV Shohet. (2010). Conditional HIF-1alpha expression produces a reversible cardiomyopathy. PLoS One 5:e11693.

25. Minamishima YA, J Moslehi, N Bardeesy, D Cullen, RT Bronson and WG Kaelin, Jr. (2008). Somatic inactivation of the PHD2 prolyl hydroxylase causes polycythemia and congestive heart failure. Blood 111:3236-3244.

26. Parisi Q, GG Biondi-Zoccai, A Abbate, D Santini, F Vasaturo, S Scarpa, R Bussani, AM Leone, A Petrolini, et al. (2005). Hypoxia inducible factor-1 expression mediates myocardial response to ischemia late after acute myocardial infarction. Int J Cardiol 99:337-339.

27. Holscher M, M Silter, S Krull, $M$ von Ahlen, A Hesse, $P$ Schwartz, B Wielockx, G Breier, DM Katschinski and A Zieseniss. (2011). Cardiomyocyte-specific prolyl-4-hydroxylase domain 2 knock out protects from acute myocardial ischemic injury. J Biol Chem 286:11185-11194.

28. Tsai CC, YJ Chen, TL Yew, LL Chen, JY Wang, CH Chiu and SC Hung. (2011). Hypoxia inhibits senescence and maintains mesenchymal stem cell properties through down-regulation of E2A-p21 by HIF-TWIST. Blood 117:459-469.

29. Ceradini DJ, AR Kulkarni, MJ Callaghan, OM Tepper, N Bastidas, ME Kleinman, JM Capla, RD Galiano, JP Levine and GC Gurtner. (2004). Progenitor cell trafficking is regulated by hypoxic gradients through HIF-1 induction of SDF1. Nat Med 10:858-864.

30. Calvani M, A Rapisarda, B Uranchimeg, RH Shoemaker and G Melillo. (2006). Hypoxic induction of an HIF-1alpha- 
dependent bFGF autocrine loop drives angiogenesis in human endothelial cells. Blood 107:2705-2712.

31. Higgins DF, MP Biju, Y Akai, A Wutz, RS Johnson and VH Haase. (2004). Hypoxic induction of Ctgf is directly mediated by Hif-1. Am J Physiol Renal Physiol 287:F1223-F1232.

32. Kelly BD, SF Hackett, K Hirota, Y Oshima, Z Cai, S BergDixon, A Rowan, Z Yan, PA Campochiaro and GL Semenza. (2003). Cell type-specific regulation of angiogenic growth factor gene expression and induction of angiogenesis in nonischemic tissue by a constitutively active form of hypoxia-inducible factor 1. Circ Res 93:1074-1081.

33. Kitajima Y, T Ide, T Ohtsuka and K Miyazaki. (2008). Induction of hepatocyte growth factor activator gene expression under hypoxia activates the hepatocyte growth factor/ c-Met system via hypoxia inducible factor-1 in pancreatic cancer. Cancer Sci 99:1341-1347.

34. Ronkainen VP, JJ Ronkainen, SL Hanninen, H Leskinen, JL Ruas, T Pereira, L Poellinger, O Vuolteenaho and P Tavi. (2007). Hypoxia inducible factor regulates the cardiac expression and secretion of apelin. FASEB J 21:1821-1830.

35. Wolf N, W Yang, CE Dunk, I Gashaw, SJ Lye, T Ring, M Schmidt, E Winterhager and A Gellhaus. (2010). Regulation of the matricellular proteins CYR61 (CCN1) and NOV (CCN3) by hypoxia-inducible factor-1\{alpha\} and transforming-growth factor-\{beta\} 3 in the human trophoblast. Endocrinology 151:2835-2845.

36. Jun JI and LF Lau. (2010). The matricellular protein CCN1 induces fibroblast senescence and restricts fibrosis in cutaneous wound healing. Nat Cell Biol 12:676-685.

37. Bujak M and NG Frangogiannis. (2007). The role of TGF-beta signaling in myocardial infarction and cardiac remodeling. Cardiovasc Res 74:184-195.

38. Li TS, M Hayashi, H Ito, A Furutani, T Murata, M Matsuzaki and K Hamano. (2005). Regeneration of infarcted myocardium by intramyocardial implantation of ex vivo transforming growth factor-beta-preprogrammed bone marrow stem cells. Circulation 111:2438-2445.

39. Ries C, V Egea, M Karow, H Kolb, M Jochum and P Neth. (2007). MMP-2, MT1-MMP, and TIMP-2 are essential for the invasive capacity of human mesenchymal stem cells: differential regulation by inflammatory cytokines. Blood 109: 4055-4063.

40. Grotendorst GR. (1997). Connective tissue growth factor: a mediator of TGF-beta action on fibroblasts. Cytokine Growth Factor Rev 8:171-179.

41. Bennewith KL, X Huang, CM Ham, EE Graves, JT Erler, N Kambham, J Feazell, GP Yang, A Koong and AJ Giaccia. (2009). The role of tumor cell-derived connective tissue growth factor (CTGF/CCN2) in pancreatic tumor growth. Cancer Res 69:775-784.

42. Recchia AG, EM De Francesco, A Vivacqua, D Sisci, ML Panno, S Ando and M Maggiolini. (2011). The G proteincoupled receptor 30 is up-regulated by hypoxia-inducible factor-1alpha (HIF-1alpha) in breast cancer cells and cardiomyocytes. J Biol Chem 286:10773-10782.
43. Gang H, Y Hai, R Dhingra, JW Gordon, N Yurkova, Y Aviv, $\mathrm{H}$ Li, F Aguilar, A Marshall, E Leygue and LA Kirshenbaum. A novel hypoxia-inducible spliced variant of mitochondrial death gene Bnip3 promotes survival of ventricular myocytes. Circ Res 108:1084-1092.

44. Hattori K, B Heissig, K Tashiro, T Honjo, M Tateno, JH Shieh, NR Hackett, MS Quitoriano, RG Crystal, S Rafii and MA Moore. (2001). Plasma elevation of stromal cellderived factor- 1 induces mobilization of mature and immature hematopoietic progenitor and stem cells. Blood 97:3354-3360.

45. Neuss S, E Becher, M Woltje, L Tietze and W JahnenDechent. (2004). Functional expression of HGF and HGF receptor/c-met in adult mesenchymal stem cells suggest arole in cell mobilization, tissue repair and wound healing. Stem cells 22:405-414.

46. Wojakowski W, M Tendera, A Michalowska, M Majka, M Kucia, K Maslankiewicz, R Wyderka, A Ochala and MZ Ratajczak. (2004). Mobilization of CD34/CXCR4+, CD34/ CD117+, c-met + stem cells, and mononuclear cells expressing early cardiac, muscle, and endothelial markers into peripheral blood in patients with acute myocardial infarction. Circulation 110:3213-3220.

47. Rajagopalan S, J Olin, S Deitcher, A Pieczek, J Laird, PM Grossman, CK Goldman, K McEllin, R Kelly and N Chronos. (2007). Use of a constitutively active hypoxia-inducible factor-1alpha transgene as a therapeutic strategy in no-option critical limb ischemia patients: phase I dose-escalation experience. Circulation 115:1234-1243.

Address correspondence to: Dr. Pilar Sepúlveda

Regenerative Medicine and Heart Transplantation Unit Fundación para la Investigación Hospital La Fe Avda Campanar 21

Valencia 46009

Spain

E-mail: pilar.sepulveda.sanchis@gmail.com

Dr. Jose Anastasio Montero

Regenerative Medicine and Heart Transplantation Unit Fundación para la Investigación Hospital La Fe Avda Campanar 21 Valencia 46009 Spain

E-mail: montero_jos@gva.es

Received for publication June 18, 2012

Accepted after revision August 4, 2012

Prepublished on Liebert Instant Online August 8, 2012 


\section{This article has been cited by:}

1. Peter A. Galie, Jan P. Stegemann. 2014. Injection of mesenchymal stromal cells into a mechanically stimulated in vitro model of cardiac fibrosis has paracrine effects on resident fibroblasts. Cytotherapy 16:7, 906-914. [CrossRef]

2. Suna Wang, Yifu Zhou, Oleg Andreyev, Robert F. Hoyt, Avneesh Singh, Timothy Hunt, Keith A. Horvath. 2014. Overexpression of FABP3 inhibits human bone marrow derived mesenchymal stem cell proliferation but enhances their survival in hypoxia. Experimental Cell Research. [CrossRef]

3. Bingqing Huang, Juying Qian, Jianying Ma, Zheyong Huang, Yunli Shen, Xueying Chen, Aijun Sun, Junbo Ge, Haozhu Chen. 2014. Myocardial transfection of hypoxia-inducible factor-1 $\alpha$ and co-transplantation of mesenchymal stem cells enhance cardiac repair in rats with experimental myocardial infarction. Stem Cell Research \& Therapy 5:1, 22. [CrossRef]

4. Junfang Wu, Jie Niu, Xiaopeng Li, Xianwei Wang, Zhikun Guo, Fenxi Zhang. 2014. TGF- $\beta 1$ induces senescence of bone marrow mesenchymal stem cells via increase of mitochondrial ROS production. BMC Developmental Biology 14:1, 21. [CrossRef]

5. Fenxi Zhang, Junfang Wu, Ming Lu, Huaibin Wang, Huigen Feng. 2013. 5-Azacytidine inhibits proliferation and induces apoptosis of mouse bone marrow-derived mesenchymal stem cells. Toxin Reviews 32:4, 55-59. [CrossRef]

6. Shan Ping Yu, Zheng Wei, Ling Wei. 2013. Preconditioning Strategy in Stem Cell Transplantation Therapy. Translational Stroke Research. [CrossRef] 